\title{
Inflection-Point Nutrition Support Determined by Oral Mucosal Apoptosis Rate Is a Novel Assessment Strategy for Personalized Nutrition: A Prospective Cohort Study
}

\author{
Chun Gao ${ }^{\dagger}$, Zike Li ${ }^{\dagger}$, Sheng Zhang, Dengyi Cao, Yang Yu, Yujie Zhang, Hao Chen, Dehua Fu and Jianping Gong * \\ Department of Gastrointestinal Surgery, Tongji Hospital, Tongji Medical College, Huazhong University of Science \\ and Technology, Wuhan 430000, China; gaochun75@hotmail.com (C.G.); d202181987@hust.edu.cn (Z.L.); \\ aloof3737@126.com (S.Z.); caodengyi1986@126.com (D.C.); topyy@aliyun.com (Y.Y.); \\ yujiezhang@outlook.com (Y.Z.); chenyisheng2020@163.com (H.C.); fdh1257919297@163.com (D.F.) \\ * Correspondence: jpgong@tjh.tjmu.edu.cn \\ t These authors contributed equally to this work.
}

Citation: Gao, C.; Li, Z.; Zhang, S.; Cao, D.; Yu, Y.; Zhang, Y.; Chen, H.; Fu, D.; Gong, J. Inflection-Point Nutrition Support Determined by Oral Mucosal Apoptosis Rate Is a Novel Assessment Strategy for Personalized Nutrition: A Prospective Cohort Study. J. Pers Med. 2022, 12, 358. https://doi.org/ 10.3390/jpm12030358

Academic Editor:

Emilio González-Jiménez

Received: 10 January 2022

Accepted: 22 February 2022

Published: 26 February 2022

Publisher's Note: MDPI stays neutral with regard to jurisdictional claims in published maps and institutional affiliations.

Copyright: (C) 2022 by the authors. Licensee MDPI, Basel, Switzerland. This article is an open access article distributed under the terms and conditions of the Creative Commons Attribution (CC BY) license (https:// creativecommons.org/licenses/by/ $4.0 /)$

\begin{abstract}
Background: Energy intake and nutritional status influences a patient's recovery from major abdominal surgery. The aim of this study is to explore and validate the clinical feasibility of an inflection-point nutrition strategy for personalized nutrition in gastric cancer patients after surgery. Methods: We conducted a prospective cohort study from a single tertiary referral hospital. Patients diagnosed with gastric cancer who met the inclusion criteria were included in this study. We collected the demographic and clinic pathological characteristics of included patients. Patients were divided into a formular nutrition (FN) and inflection-point nutrition (IPN) group. We monitored the perioperative dynamics of the oral mucosal epithelia cell apoptosis rate. Predictive factors for inflection phenomenon were investigated in univariate and multivariate analysis. Results: A total of 53 gastric cancer patients were included. A total of $30(56.6 \%)$ patients showed the inflection phenomenon, with $9(34.6 \%)$ patients in the FN group and $21(77.8 \%)$ patients in the IPN group, respectively. We found that patients with the inflection phenomenon had a shorter duration of hospital stay compared to patients without the inflection phenomenon $(p=0.04)$. In multivariate analysis, independent predictive factors for inflection phenomenon were age $(p=0.015)$, operation time $\leq 300 \mathrm{~min}(p=0.012)$, and average energy intake $\geq 25 \mathrm{Kcal} / \mathrm{kg} /$ day $(p=0.038)$. Conclusions: Our findings for the first time revealed that the oral epithelial cell apoptosis rate can promptly reflect the patients' perioperative nutrition needs. Meanwhile, we developing a novel and feasible nutrition therapy guided by the oral epithelial cell apoptosis rate is novel in gastric cancer patients that have undergone laparoscopic gastrectomy.
\end{abstract}

Keywords: inflection-point nutrition; gastric cancer; apoptosis; nutritional support; postoperative recovery

\section{Introduction}

Gastric cancer (GC) is a common malignancy in the digestive system and a leading cause of cancer death [1]. Surgery and perioperative chemotherapy were standard treatments for advanced gastric cancer [2-4]. Postoperative complications after gastrectomy with lymphadenectomy was associated with heavy morbidity and mortality in gastric cancer patients [5]. Postoperative complications may result in prolonged hospital stay, delayed postoperative chemotherapy, and an increased economic and psychological burden. Therefore, clinicians have conducted studies to investigate the risk factors for postoperative complications and relevant interventions.

Risk factors such as old age, malnutrition, comorbidities, and impaired immune function may relate to postoperative complications and delayed recovery from surgery [6-8]. Perioperative nutritional status has an important impact on the surgical outcome. Malnutrition and insufficient nutrition intake may lead to increased morbidity and mortality 
after major abdominal surgery $[9,10]$. Recent advances in perioperative management as enhanced recovery after surgery (ERAS) have had a profound contribution to personalized treatment and improved recovery after a major surgery [11,12]. However, traditional nutrition assessment methods are not accurate in precisely evaluating patients' nutritional needs. In addition, a physical measurement of body composition and monitoring of serum proteins fail to promptly reflect pathophysiological nutritional changes in patients [13-15]. Therefore, clinicians have been investigating a novel strategy that can precisely reflect the perioperative nutrition status and energy needs of the patients.

In our previous study, we found that the oral mucosal cell apoptosis rate significantly correlated with the nutritional status in gastric cancer patients. Malnourished patients demonstrated a significant decreased apoptosis rate of the oral mucosal cell compared to patients with a normal nutrition status [16]. Measuring the oral mucosal apoptosis rate was a non-invasive technique and could be a precise nutritional assessment method. In this context, we aim to evaluate the value of the oral epithelial cell apoptosis rate detection in predicting patients' perioperative nutrition needs. Furthermore, we attempt to establish a clinical nutrition therapy strategy guided by oral epithelial cell apoptosis rate detection in gastric cancer patients that have undergone laparoscopic gastrectomy with D2 lymphadenectomy.

\section{Methods}

\subsection{Study Design and Participants}

We performed a prospective cohort study in a single institution from April 2019 to December 2020. In total, 53 gastric cancer patients that underwent laparoscopic gastrectomy with D2 lymphadenectomy according to the Japanese Gastric Cancer Treatment Guidelines [17] were included in our study. The inclusion criteria were: (1) Patients with no nutritional risk (screened by NRS-2002); (2) patients with a histopathological confirmed diagnosis of gastric cancer and had undergone operation as laparoscopic gastrectomy with D2 lymph node dissection; (3) no previous history of malignancies or chemotherapy; (4) an absence of diabetes mellitus, hyperthyroidism, or other metabolic diseases; and (5) having no lesions of oral mucosa. Exclusion criteria included: (1) Intraoperative conversion to palliative tumor resection; (2) patients with a poor general status (Karnofsky < 80, Eastern Cooperative Oncology Group (ECOG) > 1); and (3) patients with a recent history of severe heart, lung, kidney, or liver failure.

This study was approved by the institutional medical ethics committee (TJ-20130803) and registered at clinicaltrials.gov under identification code ID: NCT02102659 and trial name: Biological Assessment of Clinical Nutrition and Its Application. This study was carried out in accordance with all aspects complying with the 1964 Helsinki Declaration and later versions. All participants provided their written informed consent.

\subsection{Allocation of Patients}

We applied a random block method with a 1:1 allocation for randomization using SAS software (version 9.4, SAS Institute Inc., Cary, NC, USA). A total of 169 patients were recruited for assessment. After the initial evaluation, 116 patients were excluded due to their poor general status, history of other malignancies, chemotherapy, or severe comorbidities. Finally, 53 eligible patients were randomly assigned to two groups: The formular nutrition (FN) group $(n=26)$ and inflection-point nutrition (IPN) group $(n=27)$. This study was conducted and presented in compliance with the Strengthening the Reporting of Cohort Studies in Surgery (STROCSS) guideline [18] (Supplemental Table S1). Figure 1 shows the flow diagram of participants through the study. 


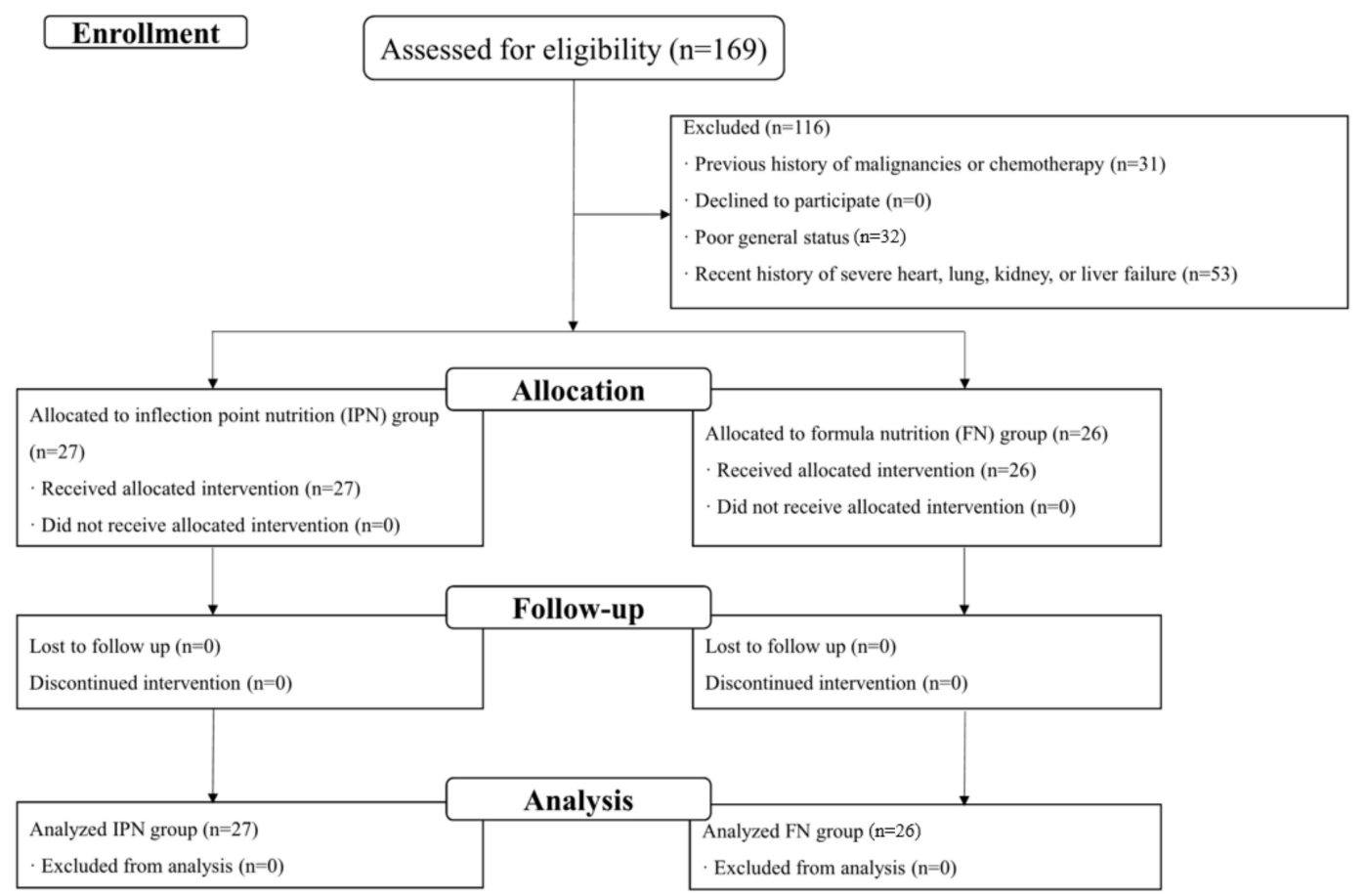

Figure 1. Flow diagram of the sequence through the stages of an observational.

\subsection{Monitoring of Apoptosis Rate of EOMECs}

In all included patients, the apoptosis rate of exfoliated oral mucosal epithelial cells (EOMECs) was monitored from pre-operative day 1 to post-operative day 7 by employing the following methods: In brief, at early morning, after rinsing mouth with saline, the mucosal epithelial cells of patients were collected through scrubbing their mouths with a sterile cotton swab several times. The swab was then put into a sputum culture cup containing $15 \mathrm{~mL} 0.9 \%$ normal saline. After slight shaking, the solution was filtered through a 500-mesh sieve (BD Falcon) and centrifuged at $800 \mathrm{r} / \mathrm{min}$ for $5 \mathrm{~min}$. The sediment was fixed with $80 \%$ ethanol and stored in a refrigerator at $-20^{\circ} \mathrm{C}$ for later use. Within $12 \mathrm{~h}$, the cell suspension was taken out, shaken on a shaker for $10 \mathrm{~s}$, and filtered through a $100-\mu \mathrm{m}$ sieve (BD Falcon). Afterwards, the cell suspension was collected and centrifuged at $1200 \mathrm{r} / \mathrm{min}$ for $5 \mathrm{~min}$. After removal of alcohol and washing with PBS, the sample was again centrifuged at $1200 \mathrm{r} / \mathrm{min}$ for $5 \mathrm{~min}$. A total of $500 \mathrm{~mL}$ of $0.2 \mathrm{~mol} / \mathrm{L}$ phosphate-citrate (PC) buffer (96 parts of $0.2 \mathrm{M} \mathrm{Na}_{2} \mathrm{HPO}_{4}$ and 4 parts of $0.1 \mathrm{M}$ citric acid, $\mathrm{pH} 7.8$ ) was added into the cell suspension. After shaking, the sample was stored at room temperature for $30 \mathrm{~min}$, washed twice with PBS, and centrifuged at $1200 \mathrm{r} / \mathrm{m}$ for $5 \mathrm{~min}$. After the addition of $5 \mathrm{mg} / \mathrm{mL}$ RNase $10 \mu \mathrm{L}, 10 \times$ PI (propidium iodide) $10 \mu \mathrm{L}$, and $180 \mu \mathrm{L}$ PBS, the sample was stored at $4{ }^{\circ} \mathrm{C}$ in darkness, overnight and then analyzed by FACSort flow cytometry (BectonDickinson, San Jose, CA, USA) [19].

\subsection{Clinical Management and Nutritional Support}

Both patients in the FN and IPN group received intravenous nutrition support from postoperative day 1 to day 7 . The total non-protein nutrition supplement included glucose and lipid (ratio 3:1), and electrolyte, micro-element, and vitamins according to the nutritional status of subjects and followed the standard procedure of the hospital. The doses of nutritional components were selected according to the Chinese Society for Parenteral and Enteral Nutrition (CSPEN) guideline on parenteral nutrition for patients undergoing surgery [20].

In the FN group, the daily non-protein energy need was calculated as follows: Patients were given the basal energy expenditure (BEE) on postoperative day 1 (BEE was calculated 
with the Harris-Benedict equations (for males: $\mathrm{BEE}=(66.47+13.75 \times$ Weight $(\mathrm{kg})+$ $5.00 \times$ Height $(\mathrm{cm})-6.78 \times$ Age $(Y)) \times 0.9$; for females: $\mathrm{BEE}=[655.10+9.56 \times$ Weight $(\mathrm{kg})$ $+1.85 \times$ Height $(\mathrm{cm})-4.68 \times$ Age $(\mathrm{Y})] \times 0.9)[21,22]$. From post-operative day 2, total daily energy expenditure (TDEE), after correction, was administered. In this study, the correction coefficient was empirically determined as 1.2. (Corrected equations: for males: TDEE $=[66.47+13.75 \times$ Weight $(\mathrm{kg})+5.00 \times$ Height $(\mathrm{cm})-6.78 \times$ Age $(\mathrm{Y})] \times 1.2$; for females: TDEE $=(655.10+9.56 \times$ Weight $(\mathrm{kg})+1.85 \times$ Height $(\mathrm{cm})-4.68 \times$ Age $(\mathrm{Y})) \times 1.2$. The corrected TDEE was given until discharge. In the IPN group, the patients were given BEE on post-operative day 1, and corrected TDEE was administered on post-operative day 2. Thereafter, the non-protein calorie supply was increased by about $2 \mathrm{Kcal} /(\mathrm{kg} \cdot \mathrm{d})$ until an inflection point occurred on the curve of the apoptosis rate of EOMECs or symptoms of nutrition intolerance developed. The amount of nutrition supply at the inflection point was maintained till discharged. The total daily energy supply in the IPN group was adjusted according to the mucosal apoptosis rate.

The primary endpoint of this study was to evaluate the impact of the inflection-point nutrition supply on postoperative hospital stay (the number of days from the day of operation until the date of discharge) and complication (according to the Clavien-Dindo criteria [23]). The secondary endpoints include the value of the oral epithelial cell apoptosis rate detection in predicting patients' perioperative nutrition needs and the analyses of factors associated with the inflection phenomenon in gastric cancer patients after gastrectomy. Additionally, we recorded the following demographic and clinical data: 1. Demographic characteristics such as gender, age, body mass index (BMI), history of smoking or alcohol, and comorbidities; 2. laboratory characteristics such as complete blood count, total lymphocyte count, hemoglobin, albumin, prealbumin, serum tumor markers as carcinoembryonic antigen (CEA), and liver and kidney function tests; 3. clinical characteristics such as operation type, intra-operative blood loss, operation time, tumor invasion depth $(\mathrm{T})$, presence of lymph node metastases $(\mathrm{N})$, and tumor-node-metastasis stage (TNM); and 4. postoperative events such as first flatus and first defecation.

\subsection{Statistical Analyses}

We present categorical variables as whole numbers and percentages. Pearson chisquare test or Fisher exact tests were applied to compare the differences. We present continuous variables as the mean (standard deviation, SD)/medians (range) and analyzed with the student $t$-test or Mann-Whitney $U$ test. The cut-off value for operation time and average energy intake were determined by the receiver operating characteristic (ROC) curve. The univariate logistic regression was used to evaluate potential predictive factors for inflection phenomenon. Only factors with $p$-value $<0.1$ in univariate analysis were included in the final multivariate analysis model. Multivariate logistic regression was employed to identify independent predictive factors for inflection phenomenon. All $p$ values were reported as two-sided with a significance level of 0.05 . All statistical tests were performed in SPSS version 24.0 (IBM, Armonk, NY, USA) and graphing were performed by Graph Pad Prism version 8.00 software.

\section{Results}

\subsection{Demographic and Clinical Characteristics of Included Patients}

Between April 2019 to December 2020, 169 gastric cancer patients that had undergone laparoscopic gastrectomy with D2 lymph node dissection were initially selected for this study. After screening based on inclusion and exclusion criteria, 53 gastric cancer patients were included in final study (Figure 1). The main demographic, biochemical, and clinical parameters are summarized in Tables 1 and 2. In general, the mean age of included patients was $56.2 \pm 10.7$ with $28(52.8 \%)$ men and $25(47.2 \%)$ women. A total of $31(58.5 \%)$ and $38(71.7 \%)$ had a history of smoking and alcohol, respectively. A total of $33(62.3 \%)$ patients underwent laparoscopic distal gastrectomy, and $20(37.3 \%)$ patients underwent laparoscopic total gastrectomy. The median duration of postoperative hospital stay was 
11 days (IQR: 10-12). A total of 7 (13.2\%) patients suffered from Grade $1 \& 2$ post-operative complications. No in-hospital death was reported in this study.

Table 1. The demographic and laboratory characteristics of all patients $(n=53)$.

\begin{tabular}{|c|c|c|c|c|}
\hline Variables & $\begin{array}{l}\text { All Patients } \\
(N=53)\end{array}$ & $\begin{array}{l}\text { No inflection } \\
\text { Phenomenon }(n=23)\end{array}$ & $\begin{array}{l}\text { Inflection } \\
\text { Phenomenon }(n=30)\end{array}$ & $p$-Value \\
\hline \multicolumn{5}{|l|}{ Demographic } \\
\hline Age, mean (SD), y & $56.2 \pm 10.7$ & $53.7 \pm 11.6$ & $58.2 \pm 9.7$ & 0.130 \\
\hline Gender, Male/Female & $28 / 25$ & $12 / 11$ & $16 / 14$ & 0.933 \\
\hline Body mass index mean (SD), $\mathrm{kg} / \mathrm{m}^{2}$ & $22.3 \pm 2.4$ & $22.9 \pm 2.5$ & $21.9 \pm 2.2$ & 0.141 \\
\hline \multicolumn{5}{|l|}{ Smoking } \\
\hline No & $58.5 \%(31 / 53)$ & $56.5 \%(13 / 23)$ & $60.0 \%(18 / 30)$ & 0.799 \\
\hline Yes & $41.5 \%(22 / 53)$ & $43.5 \%(10 / 23)$ & $40.0 \%(12 / 30)$ & \\
\hline \multicolumn{5}{|l|}{ Alcohol } \\
\hline No & $71.7 \%(38 / 53)$ & $73.9 \%(17 / 23)$ & $70.0 \%(21 / 30)$ & 0.754 \\
\hline Yes & $28.3 \%(15 / 53)$ & $26.1 \%(6 / 23)$ & $30.0 \%(9 / 30)$ & \\
\hline \multicolumn{5}{|l|}{ Comorbidity } \\
\hline No & $88.7 \%(47 / 53)$ & $91.3 \%(21 / 23)$ & $86.7 \%(26 / 30)$ & 0.597 \\
\hline Yes & $11.3 \%(6 / 53)$ & $8.7 \%(15 / 23)$ & $13.3 \%(4 / 30)$ & \\
\hline \multicolumn{5}{|l|}{ Laboratory } \\
\hline Albumin $(\mathrm{g} / \mathrm{L})$, mean $(\mathrm{SD})$ & $38.4 \pm 3.9$ & $39.3 \pm 3.6$ & $37.7 \pm 4.1$ & 0.144 \\
\hline Prealbumin (mg/L), mean (SD) & $225.6 \pm 44.2$ & $214.1 \pm 41.9$ & $234.5 \pm 44.7$ & 0.095 \\
\hline $\begin{array}{l}\text { Absolute neutrophil count }\left({ }^{*} 10^{9} / \mathrm{L}\right) \text {, } \\
\text { mean (SD) }\end{array}$ & $3.2 \pm 1.1$ & $3.2 \pm 1.1$ & $3.1 \pm 1.2$ & 0.780 \\
\hline $\begin{array}{l}\text { Absolute lymphocyte count }\left(* 10^{9} / \mathrm{L}\right) \text {, } \\
\text { mean (SD) }\end{array}$ & $1.9 \pm 0.6$ & $1.8 \pm 0.6$ & $1.9 \pm 0.5$ & 0.721 \\
\hline Hemoglobin $(\mathrm{g} / \mathrm{L})$, mean $(\mathrm{SD})$ & $122.4 \pm 26.5$ & $123.0 \pm 24.5$ & $121.7 \pm 28.3$ & 0.870 \\
\hline \multicolumn{5}{|l|}{ Preoperative serum CEA } \\
\hline Normal $(<5 \mathrm{ng} / \mathrm{mL})$ & $88.7 \%(47 / 53)$ & $82.6 \%(19 / 23)$ & $93.3 \%(28 / 30)$ & 0.222 \\
\hline Elevated $(\geq 5 \mathrm{ng} / \mathrm{mL})$ & $11.3 \%(6 / 53)$ & $17.4 \%(4 / 23)$ & $6.7 \%(2 / 30)$ & \\
\hline \multicolumn{5}{|l|}{ Preoperative serum CA19-9 } \\
\hline Normal $(<37 \mathrm{IU} / \mathrm{mL})$ & $96.2 \%(51 / 53)$ & $95.7 \%(22 / 23)$ & $96.7 \%(29 / 30)$ & 0.848 \\
\hline Elevated ( $\geq 37 \mathrm{IU} / \mathrm{mL})$ & $3.8 \%(2 / 53)$ & $4.3 \%(1 / 23)$ & $3.3 \%(1 / 30)$ & \\
\hline
\end{tabular}

For $p$-value: The asterisk superscript indicates significant difference. SD, standard deviation; CEA, carcinoembryonic antigen.

Table 2. The perioperative characteristics of all patients $(n=53)$.

\begin{tabular}{|c|c|c|c|c|}
\hline Variables & $\begin{array}{l}\text { All Patients } \\
(N=53)\end{array}$ & $\begin{array}{l}\text { No inflection } \\
\text { Phenomenon }(n=23)\end{array}$ & $\begin{array}{l}\text { Inflection } \\
\text { Phenomenon }(n=30)\end{array}$ & $p$-Value \\
\hline Blood loss, mL, mean (SD) & $235 \pm 114$ & $235 \pm 114$ & $222 \pm 133$ & 0.76 \\
\hline Operation time, min, mean (SD) & $324 \pm 50$ & $330 \pm 45$ & $318 \pm 54$ & 0.39 \\
\hline Operation & & & & 0.70 \\
\hline Distal gastrectomy & $62.3 \%(33 / 53)$ & $65.2 \%(15 / 23)$ & $60.0 \%(18 / 30)$ & \\
\hline Total gastrectomy & $37.7 \%(20 / 53)$ & $34.8 \%(8 / 23)$ & $40.0 \%(12 / 30)$ & \\
\hline $\begin{array}{l}\text { Average energy intake, } \mathrm{Kcal} / \mathrm{Kg} / \text { day } \\
\text { TNM stage }\end{array}$ & $27.4 \pm 3.9$ & $25.7 \pm 3.1$ & $28.8 \pm 4.1$ & $<0.01 *$ \\
\hline $\mathrm{I} / \mathrm{II}$ & $41.5 \%(21 / 53)$ & $39.1 \%(9 / 23)$ & $43.3 \%(13 / 30)$ & 0.76 \\
\hline III/IV & $58.5 \%(31 / 53)$ & $60.9 \%(14 / 23)$ & $56.7 \%(17 / 30)$ & \\
\hline $\begin{array}{l}\text { Median length of stay, day } \\
\text { Complications }\end{array}$ & $11(10-12)$ & $11(10-17)$ & $10(9-11)$ & 0.04 * \\
\hline No & $86.8 \%(46 / 53)$ & $90.0 \%(27 / 340)$ & $83.3 \%(19 / 23)$ & 0.431 \\
\hline Grade $1 \& 2$ & $13.2 \%(7 / 53)$ & $10.0 \%(3 / 30)$ & $17.4 \%(4 / 23)$ & \\
\hline Mortality & $0(0,0)$ & $0(0,0)$ & $0(0,0)$ & 1.00 \\
\hline
\end{tabular}

For $p$-value: The asterisk superscript indicates significant difference. SD, standard deviation; TNM, tumor-nodemetastasis; AC, adjuvant chemotherapy; RFS, recurrence-free survival. 


\subsection{Prevalence and Description of Inflection-Point Phenomenon}

In the inflection-point nutrition group, we found that as the nutrition supply increased, the apoptosis rate of oral mucosal epithelial cells rose to a certain point (the inflection point), and then entered a relative stable "plateau phase" (independent of further increase in nutrition intake). The above phenomenon was defined as "inflection-point phenomenon". We defined the inflection point as the point that the oral mucosa apoptosis rate does not increase with the increase of energy and fluctuates within 5\% (Figure 2A). In the FN group, 9 (34.6\%) patients experienced "inflection-point phenomenon" in the postoperative dynamic change in oral mucosal cell apoptosis. In the IPN group, 21 (77.8\%) patients experienced an "inflection-point phenomenon" (Figure 2B). In total, 30 (56.6\%) patients showed an inflection phenomenon and $23(41.1 \%)$ patients did not experience an inflection phenomenon.
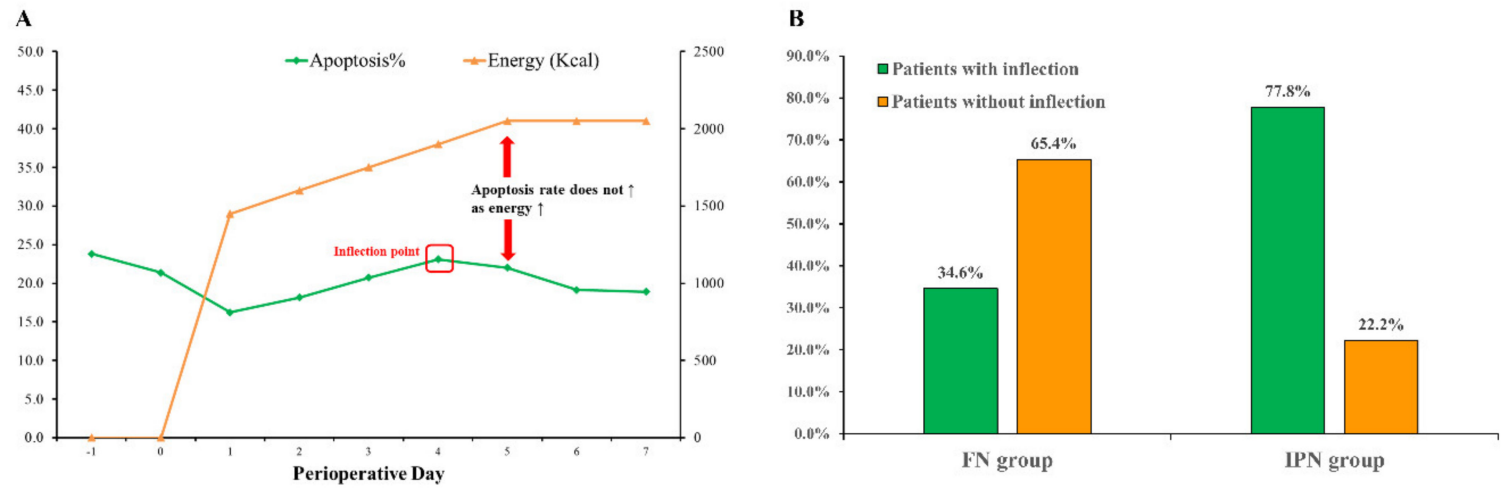

Figure 2. (A) Definition of inflection point (oral epithelial cell apoptosis rate does not increase with the increase of energy and fluctuates within 5\%). (B) The percentage of patients experienced "inflection-point phenomenon" in the IPN group and FN group.

Figure 3 demonstrates the representative figures for the inflection-point phenomenon. In general, the average apoptosis rate of oral mucosal cells decreased after surgery. In most patients with the inflection/point phenomenon, as the energy supply increased, the apoptosis rate of oral mucosal cells reached the inflection point on postoperative day 2 to day 4 $(21 / 30,70 \%)$. Supplemental Figure S1 demonstrated the representative figures for patients without an inflection-point phenomenon.

\subsection{Predictive Factors Associated with Inflection Phenomenon}

Predictive factors for inflection-point phenomenon were identified from univariate analysis (Table 3). Univariate analysis revealed that age ( $>55 \mathrm{y}$ vs. $\leq 55 \mathrm{y}$, hazard ratio $(\mathrm{HR})=3.75, p=0.024)$, body mass index $\left(\leq 24 \mathrm{~kg} / \mathrm{m}^{2}\right.$ vs. $>24 \mathrm{~kg} / \mathrm{m}^{2} \mathrm{HR}=4.18$, $p=0.037)$, decreased serum albumin $(<35 \mathrm{~g} / \mathrm{L}, \mathrm{HR}=4.44, p=0.04)$, operation time $(\leq 300 \mathrm{~min}$ vs. $>300 \mathrm{~min}, \mathrm{HR}=4.55, p=0.018)$, and average energy intake $(\geq 25 \mathrm{Kcal} / \mathrm{kg} / \mathrm{day}$ vs. $<25 \mathrm{Kcal} / \mathrm{kg} /$ day, $\mathrm{HR}=5.96, p<0.01$ ) were related to inflection phenomenon (Table 3 ). Moreover, multivariate logistic regression analysis showed that age $(>55 \mathrm{y})$, operation time ( $\leq 300 \mathrm{~min})$, and average energy intake $(\geq 25 \mathrm{Kcal} / \mathrm{kg} /$ day) were identified as independent predictive factors associated with inflection phenomenon, with the HR of $6.8(p=0.015$, 95\%CI 1.45-31.84), 7.69 ( $p=0.012,95 \%$ CI 1.59-33.33), and 5.32 ( $p=0.038,95 \%$ CI 1.10-25.79), respectively. The details of univariate and multivariate analysis are listed in Table 3.

\subsection{Inflection-Point Nutrition Supply and Postoperative Recovery}

Table 4 shows the postoperative characteristics in two groups. In general, the overall rate of postoperative complication was 13.2\% (7/53). Postoperative complications were observed in 3 patients (11.1\%) in the IFN group and 4 patients $(15.4 \%)$ in the FN group $(p=0.65)$. The median times to postoperative first flatus were $60 \mathrm{~h}$ (IQR: 48, 72) after 
surgery in the IFN group and $68 \mathrm{~h}$ (IQR: 48,80) after surgery $(p=0.56)$ in the FN group. There were no significant differences in total hospital stay and postoperative hospital stay between two groups ( $p=0.71$ and 0.98$)$.
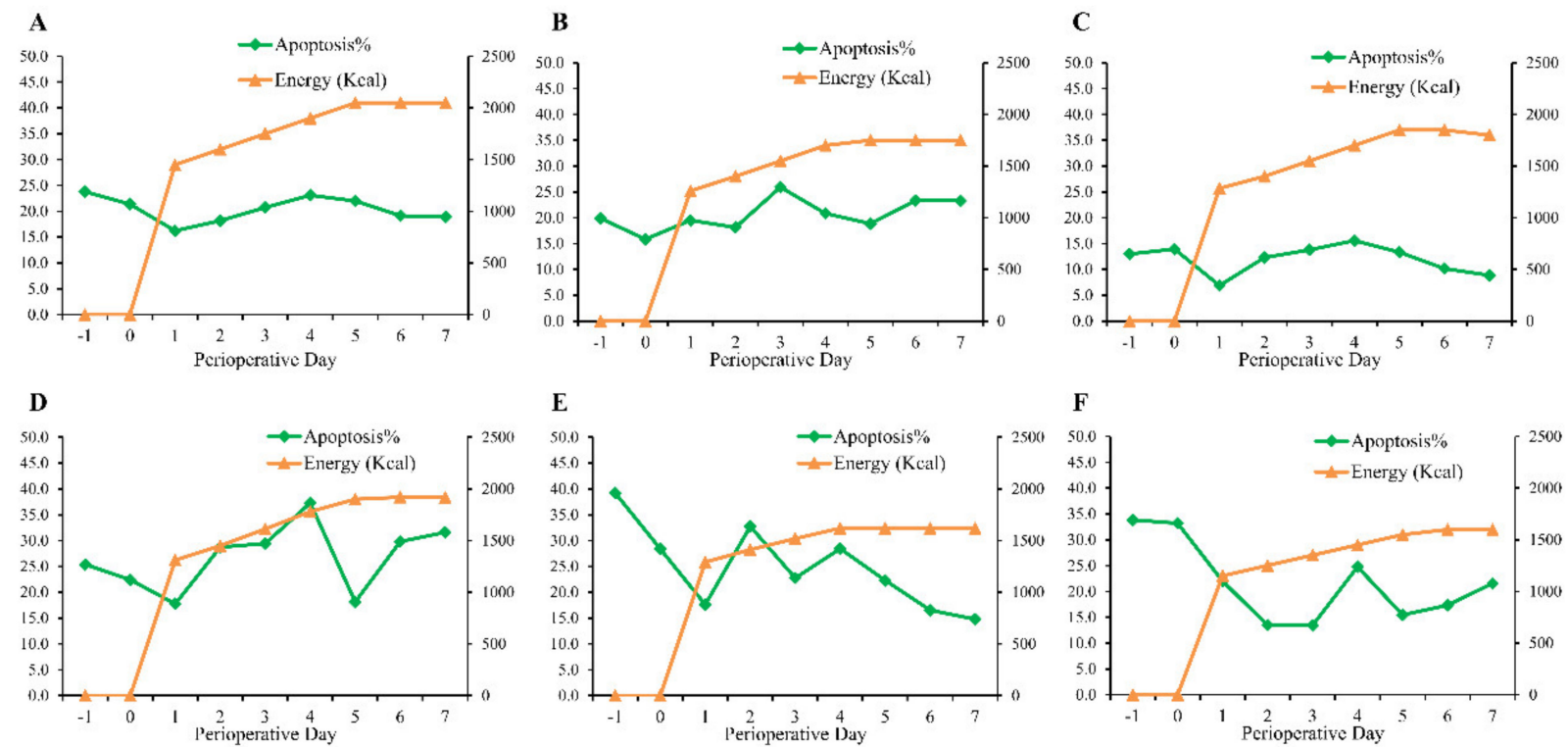

Figure 3. Representative figures for patients with inflection-point phenomenon. (A-F, 6 patients from the IPN group). $x$ axis indicates perioperative day, $y$ axis (left) indicates oral epithelial cell apoptosis rate (\%), and $y$ axis (right) indicates total energy intake (Kcal).

Table 3. Univariate and multivariate logistic regression analyses of factors associated with the inflection phenomenon $(n=53)$.

\begin{tabular}{|c|c|c|c|c|}
\hline \multirow[b]{3}{*}{ Variable } & \multicolumn{4}{|c|}{ Inflection Phenomenon } \\
\hline & \multicolumn{2}{|l|}{ Univariate } & \multicolumn{2}{|l|}{ Multivariate } \\
\hline & HR (95\%CI) & $p$ & HR (95\%CI) & $p$ \\
\hline \multicolumn{5}{|l|}{ Age } \\
\hline$\leq 55 \mathrm{y}$ & $1(\operatorname{Ref})$ & & 1 (Ref) & \\
\hline$>55 \mathrm{y}$ & $3.75(1.19-11.79)$ & 0.024 * & $6.80(1.45-31.84)$ & $0.015^{*}$ \\
\hline \multicolumn{5}{|l|}{ Gender } \\
\hline Male & 1 (Ref) & & $\mathrm{N} / \mathrm{A}$ & \\
\hline Female & $1.05(0.35-3.11)$ & 0.93 & & \\
\hline \multicolumn{5}{|c|}{ Body mass index, $\mathrm{kg} / \mathrm{m}^{2}$} \\
\hline$>24$ & $1(\operatorname{Ref})$ & & 1 (Ref) & \\
\hline$\leq 24$ & $4.18(1.09-16.04)$ & 0.037 * & $5.83(0.89-38.01)$ & 0.065 * \\
\hline \multicolumn{5}{|l|}{ Smoking } \\
\hline No & 1 (Ref) & & $\mathrm{N} / \mathrm{A}$ & \\
\hline Yes & $0.87(0.29-2.61)$ & 0.80 & & \\
\hline \multicolumn{5}{|l|}{ Alcohol } \\
\hline No & 1 (Ref) & & $\mathrm{N} / \mathrm{A}$ & \\
\hline Yes & $1.21(0.38-4.09)$ & 0.75 & & \\
\hline Comorbidity & & & $\mathrm{N} / \mathrm{A}$ & \\
\hline No & 1 (Ref) & & & \\
\hline Yes & $1.62(0.27-9.70)$ & 0.60 & & \\
\hline \multicolumn{5}{|l|}{ Albumin } \\
\hline$\geq 35 \mathrm{~g} / \mathrm{L}$ & $1(\operatorname{Ref})$ & & NS $(p=0.902)$ & \\
\hline$<35 \mathrm{~g} / \mathrm{L}$ & $4.44(1.08-18.32)$ & $0.04 *$ & & \\
\hline Prealbumin & $1.01(1.00-1.03)$ & 0.105 & $\mathrm{~N} / \mathrm{A}$ & \\
\hline
\end{tabular}


Table 3. Cont.

\begin{tabular}{|c|c|c|c|c|}
\hline & \multicolumn{4}{|c|}{ Inflection Phenomenon } \\
\hline & Univariate & & Multivariate & \\
\hline Hemoglobin & $1.00(0.98-1.02)$ & 0.87 & $\mathrm{~N} / \mathrm{A}$ & \\
\hline \multicolumn{5}{|l|}{ TNM stage } \\
\hline $\mathrm{I} / \mathrm{II}$ & 1 (Ref) & & $\mathrm{N} / \mathrm{A}$ & \\
\hline III/IV & $0.84(0.28-2.54)$ & 0.76 & & \\
\hline \multicolumn{5}{|l|}{ Operation time } \\
\hline$>300 \mathrm{~min}$ & $1(\operatorname{Ref})$ & & 1 (Ref) & \\
\hline$\leq 300 \mathrm{~min}$ & $4.55(1.30-16.67)$ & $0.018^{*}$ & $7.69(1.59-33.33)$ & 0.012 * \\
\hline Blood loss & $1.00(1.00-1.01)$ & 0.76 & $\mathrm{~N} / \mathrm{A}$ & \\
\hline \multicolumn{5}{|l|}{ Operation } \\
\hline Distal gastrectomy & 1 (Ref) & & $\mathrm{N} / \mathrm{A}$ & \\
\hline Total gastrectomy & $1.25(0.41-3.86)$ & 0.70 & & \\
\hline \multicolumn{5}{|l|}{ Average energy intake } \\
\hline$<25 \mathrm{Kcal} / \mathrm{kg} /$ day & $1(\operatorname{Ref})$ & & 1 (Ref) & \\
\hline$\geq 25 \mathrm{Kcal} / \mathrm{kg} /$ day & $5.96(1.57-22.60)$ & $<0.01 *$ & $5.32(1.10-25.79)$ & 0.038 * \\
\hline \multicolumn{5}{|l|}{ Complication } \\
\hline No & 1 (Ref) & & $\mathrm{N} / \mathrm{A}$ & \\
\hline Yes & $0.53(0.11-2.64)$ & 0.44 & & \\
\hline
\end{tabular}

For $p$-value: The asterisk superscript indicates significant difference. HR, hazard ratio; TNM, tumor-nodemetastasis; N/A, not applicable; NS, no significant difference.

Table 4. Postoperative recovery of patients received inflection-point nutrition (IPN) and formular nutrition $(\mathrm{FN})(n=53)$.

\begin{tabular}{llll}
\hline Variables & $\begin{array}{l}\text { Inflection-Point } \\
\text { Nutrition Group }(\boldsymbol{n}=\mathbf{2 7})\end{array}$ & $\begin{array}{l}\text { Formular Nutrition } \\
\text { Group }(\boldsymbol{n}=\mathbf{2 6})\end{array}$ & $p$-Value \\
\hline First flatus, h, median (IQR) & $60(48,72)$ & $68(48,80)$ & 0.56 \\
Overall complications & $3(11.1 \%)$ & $4(15.4 \%)$ & 0.65 \\
$\quad$ Fever & 0 & 1 & \\
$\quad$ Pulmonary infection & 0 & 1 \\
Small amount of pleural effusion & 2 & 0 \\
$\quad 1$ & 0 \\
$\quad$ Wastroparesis & 0 & 1 & \\
$\quad$ Intraluminal bleeding & 0 & 1 & \\
Total hospital stay, days, median (IQR) & $18(16,21)$ & $17(15,24)$ & 0.71 \\
Postoperative hospital stay, days, median (IQR) & $11(10,12)$ & $11(9,13)$ & 0.98 \\
\hline
\end{tabular}

\section{Discussion}

The nutritional status influenced the short-term and long-term outcome in patients with gastric cancer. In this prospective cohort study, we investigated the value of oral epithelial cell apoptosis rate detection in predicting patients' nutrition needs. For the first time we described the inflection-point phenomenon and applied it in a novel clinical nutrition therapy strategy. In our study, $30(56.6 \%)$ patients experienced inflection-point phenomenon. We explored the potential predictive factors for the inflection phenomenon, revealing that age $(>55 \mathrm{y})$, shorter operation time ( $\leq 300 \mathrm{~min})$, and sufficient average energy intake ( $\geq 25 \mathrm{Kcal} / \mathrm{kg} /$ day) were independent predictive factors (Table 3). The inflection phenomenon may positively associate with postoperative recovery. Therefore, sufficient postoperative energy supply may be a benefit for enhanced recovery after surgery.

Trauma caused by the surgery procedures will lead to an activated systemic inflammatory response and increased metabolic demands. Therefore, adequate nutrition intake was essential for optimal postoperative recovery after major abdominal surgery. According to the recommendation from the European Society for Clinical Nutrition and Metabolism (ESPEN), cancer patients should receive $1.5 \mathrm{~g}$ protein $/ \mathrm{kg} /$ day and $25-30 \mathrm{kcal} / \mathrm{kg} /$ day for energy intake after major abdominal surgery [24]. Malnutrition and acute muscle loss 
were risk factors for delayed postoperative recovery and postoperative complication after gastrectomy [25-27]. Deficiency in traditional nutritional evaluation and supply methods were major causes for inadequate postoperative nutrition intake. It has been reported that most patients that underwent major abdominal surgery did not consume adequate protein and energy after surgery [28]. Inadequate protein and energy intake may be correlated with poor surgical outcomes such as higher complication risk and longer hospital stay [29].

In this study, we developed a novel nutrition therapy (inflection-point nutrition) based on the apoptosis rate of patients' mucosa epithelial cells. Accurate nutrition assessment is essential for effective nutrition support therapy. In our previous study, we found that the apoptosis/proliferation ratio (A/P) of exfoliated oral mucosal epithelial cells (EOMECs) varied and associated with the change of body nutritional status. The rate of both apoptosis and proliferation was reduced in patients with malnutrition [19]. Oral epithelial cells were cells with active renewal and a strong proliferative state. The apoptosis and proliferative rate of the oral epithelial cell can be affected by the change of nutrition status of the body. Some animal studies have found that malnutrition leads to a lower apoptosis rate [30] while others indicate that malnutrition is associated with a significant increase of spontaneously apoptotic cells in the thymus and spleen [31]. At this stage we were not able to explain the potential underlying mechanism of the inflection-point phenomenon. Further studies were needed to explore the biological association between oral epithelial cell apoptosis and nutritional status.

By active monitoring dynamics of patients' mucosal epithelia cell apoptosis, we found that the apoptosis rate elevated after nutrition support therapy, reflecting the efficacy of nutrition support therapy (Figure 3). After the energy supply increase, the oral epithelial cell apoptosis rate of most participants increased. The energy supply calculated by a conventional method may be insufficient for this group of patients. An increase in energy supply by nutrition therapy, results as a further increase of oral epithelial cell apoptosis. Therefore, we, for the first time, reported the inflection-point phenomenon, indicating the actual optimal energy needs of the individual patient. Appling oral epithelial cell apoptosis rate detection could identify patients' actual energy needs and evaluate the efficacy of nutrition therapy. In our preliminary study, no significant differences were found in short-term clinical outcomes in postoperative complication and hospital stay between the inflection-point nutrition (IFN) group and formular nutrition group (Table 4). More outcome measurements may be necessary to validate the clinical implication of inflection-point nutrition.

In our study, 30 (56.6\%) patients showed the inflection phenomenon. We explored the predictive factors for the inflection phenomenon and found that older age, a longer operation time, and average energy intake $\geq 25 \mathrm{Kcal} / \mathrm{kg} /$ day correlate with inflection phenomenon. Elder patients and longer operation time may result in an increase demand of total energy expenditure. Although we included patients with no nutritional risk, elder patients experiencing a higher possibility of inflection phenomenon may indicate that monitoring of oral epithelial mucosal cell apoptosis was better in reflecting the actual energy needs compared to traditional methods. Patients in the IFN group received a higher average energy intake than patients in the FN group. A higher average energy intake ( $\geq 25 \mathrm{Kcal} / \mathrm{kg} /$ day) significantly associated with the inflection phenomenon, suggesting the insufficient energy supply calculated by a traditional formular nutrition method. Interestingly, the inflection phenomenon was absent in $23(41.1 \%)$ patients. The potential reasons could be detection errors, an insufficient energy supply before inflection-point was reached, fluctuation of mucosal cell apoptosis due to traumatic stress, or unbalanced catabolism (Supplemental Figure S1).

Patients with inflection phenomenon may have a better short-term outcome after surgery. In our study, we found that patients with inflection phenomenon had a shorter duration of hospital stay compared to patients without inflection phenomenon (10 days vs. 11 days, $p=0.04$ ) (Table 2). Inflection phenomenon indicated that the energy supply could satisfy the actual need of the individual. Therefore, this finding suggested that the nutrition strategy that can 
satisfy the actual energy need of an individual would be a better nutrition delivery method. This might result in a better recovery for gastric cancer patients undergoing gastrectomy.

\section{Clinical Implication and Limitations}

This study provided novel observations and clinical feasibility of inflection-point nutrition guided by the oral mucosal cell apoptosis rate in gastric cancer patients after gastrectomy with D2 lymphadenectomy. We, for the first time, developed a nutrition protocol that can meet the actual nutrition demand of patients after surgery. Therefore, inflection-point nutrition can be conveniently applied in clinical practice for both short-term (post-operative trauma, chemotherapy, and rapid rehabilitation) and long-term (intestinal fistula, short-bowl syndrome) nutrition support therapies.

We acknowledge that the present study has several limitations. First, the sample size of our study is relatively small. With only 30 (56.6\%) patients having demonstrated inflection point phenomenon, it is difficult to draw a solid conclusion with statistical significance. Therefore, the results in our study might only be considered as indicative. Second, the primary endpoints of this study were the duration of hospital stay and postoperative complications. The correlation between inflection-point nutrition and functional outcomes regarding postoperative recovery in gastric cancer patients was not clear. Third, the defects in the sampling and detection process of the mucosal epithelial cell results in a fluctuation of the apoptosis rate. To overcome these hurdles, randomized clinical trials with a larger sample size and more clinical-pathological measurements are needed to validate the findings of our study. Meanwhile, we need to develop a more stable and reliable method to detect the apoptosis rate of mucosal epithelia cells.

\section{Conclusions}

In summary, our study for the first time indicated that the oral epithelial cell apoptosis rate could promptly reflect patients' perioperative nutrition needs. Second, inflection nutrition guided by the oral epithelial cell apoptosis rate is a novel and feasible nutrition therapy in gastric cancer patients that have undergone laparoscopic gastrectomy.

Supplementary Materials: The following supporting information can be downloaded at: https: / / www.mdpi.com/article/10.3390/jpm12030358/s1, Figure S1: the representative figures for patients without an inflection-point phenomenon; Table S1: Strengthening the Reporting of Cohort Studies in Surgery (STROCSS) guideline.

Author Contributions: All authors participated in the study design. S.Z.: Conceptualization, Writing—original draft; Z.L.: Data curation, Methodology, Software; Y.Y., D.C., H.C. and D.F.: Formal analysis, Y.Z.: Project administration; C.G. and J.G.: Conceptualization, Writing-original draft. The final version meets the major criteria recommended by the ICMJE (http:/ / www.icmje.org/ accessed on 9 January 2022). All authors have read and agreed to the published version of the manuscript.

Funding: This study was supported by grants from the National Natural Science Foundation of China (No. 81272623) and Hubei Provincial Natural Science Foundation of China (2012FKB02440).

Institutional Review Board Statement: This study was approved by the institutional medical ethics committee (TJ-20130803) and registered at clinicaltrials.gov under identification code ID: NCT02102659 and trial name: Biological Assessment of Clinical Nutrition and Its Application. This study was carried out in accordance with all aspects complying with the 1964 Helsinki Declaration and later versions.

Informed Consent Statement: Informed consent was obtained from all subjects involved in the study.

Data Availability Statement: The database used and/or analyzed during the current study is not publicly available (to maintain privacy) but can be available from the corresponding author on reasonable request.

Acknowledgments: We thank Cheng Chen for the English grammatic correction of this manuscript.

Conflicts of Interest: The authors declare that they have no competing interest. 
Ethical Approval: Ethics committee of Tongii Hospital, Tongji Medical College, Huazhong University of Science and Technology.

\section{References}

1. $\quad$ Siegel, R.L.; Miller, K.D.; Jemal, A. Cancer statistics. CA Cancer J. Clin. 2020, 70, 7-30. [CrossRef] [PubMed]

2. Sakuramoto, S.; Sasako, M.; Yamaguchi, T.; Kinoshita, T.; Fujii, M.; Nashimoto, A.; Furukawa, H.; Nakajima, T.; Ohashi, Y.; Imamura, H. Adjuvant chemotherapy for gastric cancer with S-1, an oral fluoropyrimidine. N. Engl. J. Med. 2007, 357, 1810-1820. [CrossRef] [PubMed]

3. Fuse, N.; Bando, H.; Chin, K.; Ito, S.; Yoshikawa, T.; Tsuburaya, A.; Tsuburaya, A.; Terashima, M.; Kawashima, Y.; Fukunaga, T.; et al. Adjuvant capecitabine plus oxaliplatin after D2 gastrectomy in Japanese patients with gastric cancer: A phase II study. Gastric Cancer 2017, 20, 332-340. [CrossRef] [PubMed]

4. National Comprehensive Cancer Network. Clinical Practice Guidelines in Oncology: Gastric Cancer Version 3.2020. Available online: https: / / www.nccn.org/ (accessed on 9 January 2022).

5. $\quad$ Baiocchi, G.L.; Giacopuzzi, S.; Reim, D.; Piessen, G.; Costa, P.M.; Reynolds, J.V.; Meyer, H.J.; Morgagni, P.; Gockel, I.; Santos, L.L.; et al. Incidence and Grading of Complications After Gastrectomy for Cancer Using the GASTRODATA Registry: A European Retrospective Observational Study. Ann. Surg. 2020, 272, 807-813. [CrossRef] [PubMed]

6. Coimbra, F.J.F.; de Jesus, V.H.F.; Franco, C.P.; Calsavara, V.F.; Ribeiro, H.S.C.; Diniz, A.L.; de Godoy, A.L.; de Farias, I.C.; Riechelmann, R.P.; Begnami, M.D.F.; et al. Predicting overall and major postoperative morbidity in gastric cancer patients. J. Surg. Oncol. 2019, 120, 1371-1378. [CrossRef] [PubMed]

7. Fukuda, Y.; Yamamoto, K.; Hirao, M.; Nishikawa, K.; Maeda, S.; Haraguchi, N.; Miyake, M.; Hama, N.; Miyamoto, A.; Ikeda, M.; et al. Prevalence of Malnutrition Among Gastric Cancer Patients Undergoing Gastrectomy and Optimal Preoperative Nutritional Support for Preventing Surgical Site Infections. Ann. Surg. Oncol. 2015, 22, S778-S785. [CrossRef]

8. Kanda, M. Preoperative predictors of postoperative complications after gastric cancer resection. Surg. Today 2020, 50, 3-11. [CrossRef]

9. Schiesser, M.; Kirchhoff, P.; Müller, M.K.; Schäfer, M.; Clavien, P.A. The correlation of nutrition risk index, nutrition risk score, and bioimpedance analysis with postoperative complications in patients undergoing gastrointestinal surgery. Surgery 2009, 145, 519-526. [CrossRef]

10. Jie, B.; Jiang, Z.M.; Nolan, M.T.; Zhu, S.N.; Yu, K.; Kondrup, J. Impact of preoperative nutritional support on clinical outcome in abdominal surgical patients at nutritional risk. Nutrition 2012, 28, 1022-1027. [CrossRef]

11. Aoyama, T.; Yoshikawa, T.; Sato, T.; Hayashi, T.; Yamada, T.; Ogata, T.; Cho, H. Equivalent feasibility and safety of perioperative care by ERAS in open and laparoscopy-assisted distal gastrectomy for gastric cancer: A single-institution ancillary study using the patient cohort enrolled in the JCOG0912 phase III trial. Gastric Cancer 2019, 22, 617-623. [CrossRef]

12. Kang, S.H.; Lee, Y.; Min, S.H.; Park, Y.S.; Ahn, S.H.; Park, D.J.; Kim, H.-H. Multimodal Enhanced Recovery After Surgery (ERAS) Program is the Optimal Perioperative Care in Patients Undergoing Totally Laparoscopic Distal Gastrectomy for Gastric Cancer: A Prospective, Randomized, Clinical Trial. Ann. Surg. Oncol. 2018, 25, 3231-3238. [CrossRef]

13. Waitzberg, D.L.; Correia, M.I. Nutritional assessment in the hospitalized patient. Curr. Opin. Clin. Nutr. Metab. Care 2003, 6, 531-538. [CrossRef]

14. Frankenfield, D.C.; Muth, E.R.; Rowe, W.A. The Harris-Benedict studies of human basal metabolism: History and limitations. J. Am. Diet. Assoc. 1998, 98, 439-445. [CrossRef]

15. Boullata, J.; Williams, J.; Cottrell, F.; Hudson, L.; Compher, C. Accurate determination of energy needs in hospitalized patients. J. Am. Diet. Assoc. 2007, 107, 393-401. [CrossRef] [PubMed]

16. Luo, X.; Zhou, Y.; Tao, D.; Yu, Y.; Hu, J.; Qiu, F.; Kulkarni, H.; Gong, J. Usefulness of oral mucosal epithelial cell apoptosis rate in nutritional assessment. Nutrition 2006, 22, 1032-1038. [CrossRef] [PubMed]

17. Japanese Gastric Cancer Association. Japanese gastric cancer treatment guidelines 2010 (ver. 3). Gastric Cancer 2011, 142, 113-123.

18. Agha, R.A.; Borrelli, M.R.; Vella-Baldacchino, M.; Thavayogan, R.; Orgill, D.P.; STROCSS Group. The STROCSS statement: Strengthening the reporting of cohort studies in surgery. Int. J. Surg. 2017, 46, 198-202. [CrossRef]

19. Gao, C.; Hasan, O.; Wei, X.; Zou, Y.; Yin, X.; Tao, D.; Gong, J. Assessment of nutritional status of clinical patients by determining normal range of oral mucosal apoptosis and proliferation rate. J. Huazhong Univ. Sci. Technol. 2012, 32, 680-685. [CrossRef]

20. Chinese Society for Parenteral and Enteral Nutrition; Enhanced Recovery After Surgery Committee of China Medicine Education Association. Chinese expert consensus on perioperative nutritional support in enhanced recovery after surgery (2019 edition). Chin. J. Dig. Surg. 2019, 18, 897-902. [CrossRef]

21. Harris, J.A.; Benedict, F.G. A Biometric Study of Human Basal Metabolism. Proc. Natl. Acad. Sci. USA 1918, 4, 370-373. [CrossRef] [PubMed]

22. Roza, A.M.; Shizgal, H.M. The Harris Benedict equation reevaluated: Resting energy requirements and the body cell mass. Am. J. Clin. Nutr. 1984, 40, 168-182. [CrossRef] [PubMed]

23. Clavien, P.A.; Barkun, J.; de Oliveira, M.L.; Vauthey, J.N.; Dindo, D.; Schulick, R.D.; De Santibañes, E.; Pekolj, J.; Slankamenac, K.; Bassi, C.; et al. The Clavien-Dindo Classification of Surgical Complications: Five-Year Experience. Ann. Surg. 2009, 250, 187-196. [CrossRef] [PubMed] 
24. Weimann, A.; Braga, M.; Carli, F.; Higashiguchi, T.; Hübner, M.; Klek, S.; Laviano, A.; Ljungqvist, O.; Lobo, D.N.; Martindale, R.; et al. ESPEN guideline: Clinical nutrition in surgery. Clin. Nutr. 2017, 36, 623-650. [CrossRef] [PubMed]

25. Fukuta, A.; Saito, T.; Murata, S.; Makiura, D.; Inoue, J.; Okumura, M.; Sakai, Y.; Ono, R. Impact of preoperative cachexia on postoperative length of stay in elderly patients with gastrointestinal cancer. Nutrition 2019, 58, 65-68. [CrossRef] [PubMed]

26. Gharagozlian, S.; Mala, T.; Brekke, H.K.; Kolbjørnsen, L.C.; Ullerud, Å.A.; Johnson, E. Nutritional status, sarcopenia, gastrointestinal symptoms and quality of life after gastrectomy for cancer-A cross-sectional pilot study. Clin. Nutr. ESPEN 2020, 37, 195-201. [CrossRef]

27. Looijaard, W.; Dekker, I.M.; Beishuizen, A.; Girbes, A.R.J.; Straaten, H.M.O.-V.; Weijs, P.J.M. Early high protein intake and mortality in critically ill ICU patients with low skeletal muscle area and -density. Clin. Nutr. 2020, 39, 2192-2201. [CrossRef] [PubMed]

28. Constansia, R.D.N.; Hentzen, J.E.K.R.; Hogenbirk, R.N.M.; Plas, W.Y.; Rd, M.J.E.C.; Buis, C.I.; Kruijff, S.; Klaase, J.M. Actual postoperative protein and calorie intake in patients undergoing major open abdominal cancer surgery: A prospective, observational cohort study. Nutr. Clin. Pract. 2021, 37, 183-191. [CrossRef]

29. Yeung, S.E.; Hilkewich, L.; Gillis, C.; Heine, J.A.; Fenton, T.R. Protein intakes are associated with reduced length of stay: A comparison between Enhanced RecoveryAfter Surgery (ERAS) and conventional care after elective colorectal surgery. Am. J. Clin. Nutr. 2017, 106, 44-51.

30. Cronk, D.R.; Ferguson, D.C.; Thompson, J.S. Malnutrition impairs postresection intestinal adaptation. JPEN J. Parenter. Enter. Nutr. 2000, 24, 76-80. [CrossRef]

31. Ortiz, R.; Cortés, L.; Cortés, E.; Medina, H. Malnutrition alters the rates of apoptosis in splenocytes and thymocyte subpopulations of rats. Clin. Exp. Immunol. 2009, 155, 96-106. [CrossRef] 